\title{
Percutaneous laser valvotomy with balloon dilatation of the pulmonary valve as primary treatment for pulmonary atresia
}

\author{
J M Parsons, M R Rees, J L Gibbs
}

Department of

Paediatric Cardiology, Killingbeck Hospital,

Leeds

J M Parsons

J L Gibbs

Department of

Cardiac Radiology,

Killingbeck Hospital,

Leeds

M R Rees

Correspondence to

Dr J M Parsons, Non-

Invasive Unit, Killingbeck

Hospital, York Road, Leed

LS14 6UQ.

\author{
Figure 1 Initial \\ (A) right ventricular and \\ (B) left ventricular \\ angiograms taken in a \\ right anterior oblique \\ projection showing \\ pulmonary atresia with a \\ blind ending infundibulum \\ and good sized confluent \\ pulmonary arteries \\ supplied by the ductus \\ arteriosus.
}

\begin{abstract}
A neonate with pulmonary atresia and an intact ventricular septum with a tripartite right ventricle was successfully treated by percutaneous balloon dilatation of the pulmonary valve. This was facilitated by previous laser valvotomy with a hot tip Trimedyne laser wire. There were no major complications. Four weeks later the patient was discharged home on no medication with peripheral oxygen saturations of $70 \%$ in air.
\end{abstract}

The management of patients with pulmonary atresia and an intact ventricular septum depends upon individual cardiac anatomy. In patients with a tripartite right ventricle and confluent pulmonary arteries, pulmonary valvotomy is usually favoured. ${ }^{1}$ This has the advantages of decompressing the right ventricle (which is usually at suprasystemic pressure) and at the same time permitting anterograde flow into the pulmonary trunk, thereby promoting symmetrical growth of the pulmonary arteries. It has been suggested that laser valvotomy might offer an alternative to surgical pulmonary valvotomy. ${ }^{2}$

We report our experience with percu- taneous balloon dilatation of an imperforate, dysplastic, pulmonary valve after initial laser valvotomy in a neonate with pulmonary atresia and an intact ventricular septum.

\section{Case report}

A male neonate (34 weeks' gestation and $2.2 \mathrm{~kg}$ ) was investigated at 3 weeks of age because of central cyanosis. Cross sectional echocardiography showed pulmonary atresia with an intact ventricular septum. The pulmonary trunk measured $7 \mathrm{~mm}$ in diameter; the pulmonary arteries were confluent and a similar size. The pulmonary valve was dysplastic and imperforate. The right ventricle was tripartite. Colour flow mapping confirmed that the pulmonary circulation was dependent on flow through the ductus arteriosus. There was tricuspid regurgitation and the right ventricular systolic pressure was estimated to be suprasystemic. $\mathrm{He}$ was ventilated and treatment with intravenous prostaglandin $E_{2}$ was started. Cardiac catheterisation was performed from the left femoral vein. Initial right and left ventricular angiograms performed in a right anterior oblique projection confirmed the echocardiographic findings. The atretic pulmonary valve was clearly identified (fig 1 ). The coronary artery anatomy seemed normal.
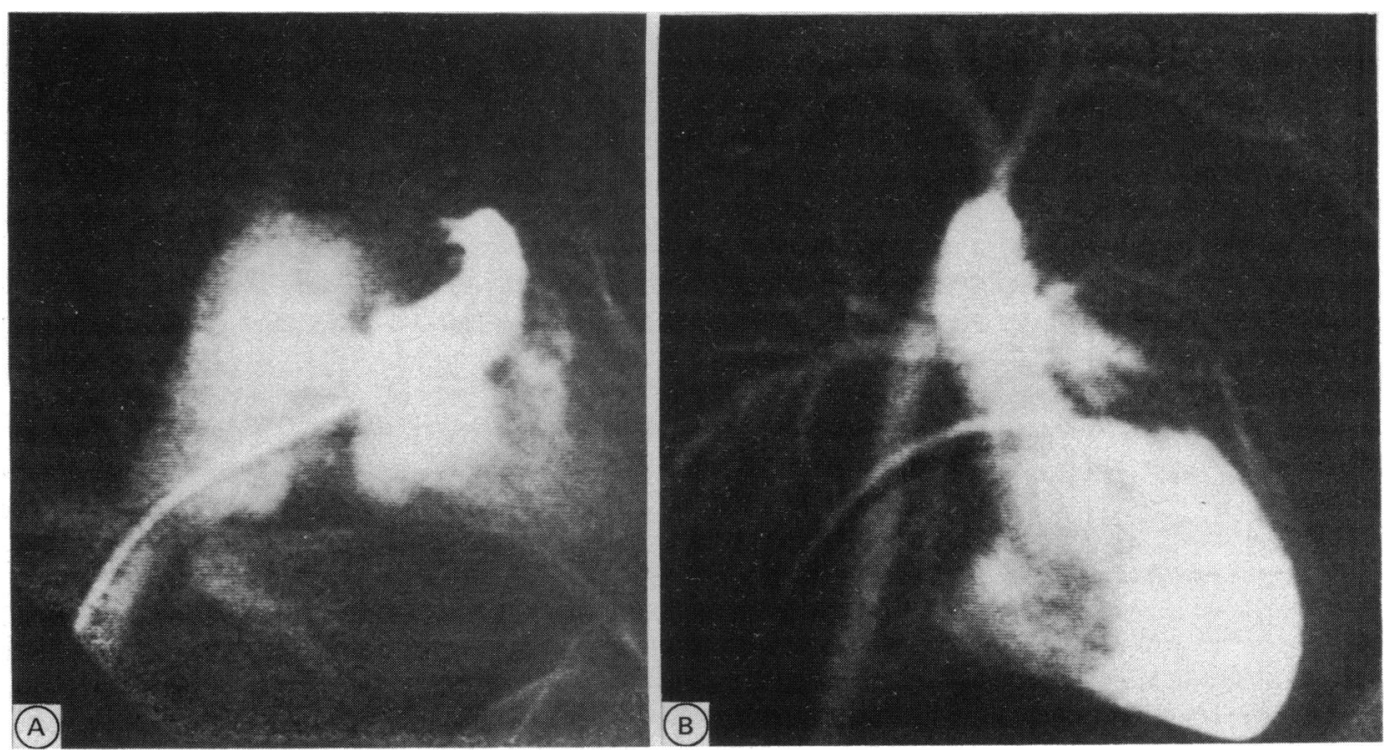
A size 4 French cobra catheter was manipulated into the blind ending infundibulum. A series of angiograms, taken in several different projections, were performed to ensure that the catheter was in a stable and suitable position, pointing posteriorly in line with the pulmonary trunk. Once this position was established a 0.018 inch Trimedyne floppy laser wire with a hot tip was passed through the catheter until it came in contact with the atretic pulmonary valve. The wire was connected to a Nd-Yag laser. Two bursts, each lasting two seconds, providing $3 \mathrm{~W}$ continuous wave laser energy proved sufficient to enable the wire to pass through the valve. The wire was kept in continuous motion with short to and fro movements in order to prevent it fusing with the delivery catheter or the intima of the pulmonary artery. The wire was then positioned in the distal right pulmonary artery without complication. We then attempted to advance the 4 French cobra catheter along the laser wire, across the pulmonary valve, and into the right pulmonary artery. Because this was not possible, an attempt was made with a $3 \mathrm{~mm}$ diameter coronary artery balloon catheter; however, this also proved unsuccessful. A 5 French cobra catheter was then repositioned within the infundibulum. A 0.014 inch high torque coronary angioplasty guide wire was advanced across the pulmonary valve through the passage created by the laser guide wire. The wire was then manipulated into a stable position within the distal left pulmonary artery. A $2 \mathrm{~mm}$ diameter coronary balloon catheter was then successfully positioned across the pulmonary valve and inflated twice. The procedure was repeated with a $5 \mathrm{~mm}$ diameter balloon catheter. Further dilatation with a larger balloon was not attempted because of recurrent episodes of supraventricular tachycardia and blood loss, estimated at approximately $50 \mathrm{ml}$. At the end of the procedure the systolic right ventricular pressure had fallen from $115 \mathrm{~mm} \mathrm{Hg}$ to $74 \mathrm{~mm}$ $\mathrm{Hg}$. A right ventricular angiogram was repeated. This showed anterograde flow into the pulmonary arteries and confirmed that there was no extravasation of contrast outside the heart (fig 2).

Figure 2 Right ventricular angiogram after laser valvotomy and balloon dilatation clearly showing anterograde filling of the pulmonary arteries.
Treatment with intravenous prostaglandin $\mathrm{E}_{2}$ was continued for three weeks. He then underwent repeat balloon dilatation of the pulmonary valve and right ventricular outflow tract with a $7 \mathrm{~mm}$ diameter balloon catheter. One week later, after treatment with prostaglandin $E_{2}$ was stopped, the ductus arteriosus closed. His peripheral oxygen saturation in air was $70 \%$ and the estimated Doppler gradient across the pulmonary valve was $40 \mathrm{~mm} \mathrm{Hg}$. He was discharged home.

\section{Discussion}

The current management for patients with pulmonary atresia and an intact ventricular septum with a tripartite right ventricle and confluent pulmonary arteries is surgical pulmonary valvotomy. Many centres then continue intravenous prostaglandin $\mathrm{E}_{2}$ to prevent the ductus arteriosus from closing to allow time for right ventricular compliance to fall. Subsequently, if there is still inadequate anterograde pulmonary flow, then an aortopulmonary shunt is usually created. ${ }^{1}$ Neonates with critical pulmonary stenosis very often have similar haemodynamic and anatomical features. A similar surgical approach has been used in the past to treat these patients. More recently, however, this group of patients has been treated successfully with percutaneous balloon dilatation. ${ }^{3}$

Interventional cardiac catheterisation techniques have until recently been unhelpful in the treatment of patients with pulmonary atresia because there has been no reliable way of crossing the atretic pulmonary valve. Our report shows that this is possible with laser energy delivered by a hot tip quartz fibre wire. The use of laser techniques to treat patients with peripheral vascular disease ${ }^{4}$ and coronary artery disease ${ }^{5}$ is well reported. Fibreoptic "wires" are manipulated through guiding catheters to the site of arterial obstruction. A laser beam is then either focused directly on to the atheromatous lesion itself, or else is focused on to a metal tip of a laser wire, which heats up and delivers sufficient thermal energy to vaporise the obstruction. The advantages of the latter method is that there is greater control and the risk of perforation is less. We, therefore, adapted this method and in the event it proved relatively straightforward to cross the patient's pulmonary valve.

We recommend that laser valvotomy should be attempted only when a satisfactory catheter position within the infundibulum can be demonstrated. It was also important that the laser wire was kept moving during delivery of the pulses of laser energy because previous experience has shown that it is possible to fuse the wire with the intima of the artery or else perforate the guiding catheter. We found cross sectional echocardiography unhelpful as a means of confirming that the laser wire was in the correct position within the pulmonary artery. We therefore depended upon $x$ ray screening in several different projections.

Although the initial laser valvotomy and the 
positioning of the laser wire into the pulmonary artery proved straightforward we experienced some difficulty in getting a catheter to advance along the wire and cross the pulmonary valve. The principal reason was that the floppy distal part of the laser wire, which was $40 \mathrm{~cm}$ long, did not provide sufficient support to enable the catheter to pass through the laser valvotomy channel. Potential solutions to this problem would be either to manipulate the laser wire through the ductus arteriosus and well into the descending aorta (which we were unable to do) thereby leaving the stiff portion of the wire across the valve or to manufacture a laser wire with a shorter floppy tip. Improvements to the taper of the catheter tip may also be helpful. Using the methods described we were able to perform the technique without major complication or morbidity. The procedure times and screening times were long; but this was an unfamiliar technique performed for the first time. Further experience should lead to a reduction in these times. The immediate result in our patient was comparable to that achievable with surgical pulmonary valvotomy, and accords with the early experience with laser valvotomy reported from Guy's Hospital. ${ }^{2}$ The long term results clearly require further evaluation. Laser valvotomy combined with percutaneous balloon dilatation of the pulmonary valve, therefore, offers great potential in the treatment of patients with pulmonary atresia.

1 Anderson RH, Macartney FJ, Shinebourne EA, Tynan M. Paediatric cardiology. Edinburgh: Churchill Livingstone,

2 Qureshi SA, Rosenthal E, Tynan M, Anjos R, Baker E. Transcatheter laser assisted pulmonic valve dilatation in pulmonic valve atresia. Am J Cardiol 1991;67:428-31.

3 Ladusans EJ, Qureshi SA, Parsons JM, Arab S, Baker EJ, Tynan M. Balloon dilatation of critical stenosis of the pulmonary valve in neonates. $B r$ Heart $J$ 1990;63:362-7.

4 Sanborn TA, Cumberland DC, Greenfield AJ, Welsh CL Guben JK. Percutaneous laser thermal angioplasty: initial results and 1 year follow up in 129 femoro-popliteal lesions. Radiology 1988;168:121-5.

5 Linnemeier TJ, Cumberland DC. Percutaneous laser coronary angioplasty without balloon angioplasty. Lancet 1989;i:154-5. 